\title{
A tetradic analysis of GIS and society using McLuhan's law of the media
}

DANIEL Z. SUI

Department of Geography, Texas A\&M University, College Station, TX 77843-3147 USA (e-mail: D-Sui@tamu.edu)

MICHAEL F. GOODCHILD

National Center for Geographic Information and Analysis, Department of Geography, University of California, Santa Barbara, CA 93106-4060 USA (e-mail: good@geog.ucsb.edu)

The social implications of GIS have been debated over the past five years among scholars in several disciplines. GIS have been either conceived by practitioners as value-free, neutral tools for problemsolving or castigated by critical social theorists as socially biased technologies serving only corporate and state interests. Neither of these polarized views is very helpful in understanding the complex relationship between GIS and society. This paper argues that GIS are increasingly becoming media for communicating various crucial social and environmental information to the general public. By reconceptualizing GIS as media, the paper conducts a detailed tetradic analysis on the social implications of GIS using Marshall McLuhan's law of media. The analysis reveals the paradoxical and ambivalent nature of GIS technology. To make GIS fulfill democratic ideals in society, this paper calls for a shift of perspective, from viewing them as instruments for problem-solving to viewing them as media for communication. This shift from instrumental to communicative rationality enables us to examine more critically and holistically how space, people and environment have been represented, manipulated and visualized in GIS and thus promotes a more critical and democratic GIS practice.
Les implications sociales des SIC ont fait l'objet d'un débat au cours des cina dernières années entre les érudits de plusieurs disciplines. Les SIG furent conçus par des praticiens comme des instruments neutres, non chargés de valeurs, pour la résolution de problèmes, maisils ont été sévèrement critiqués par des théoriciens sociaux comme étant des technologies socialement partiales, qui ne servent que les intérêts des grandes entreprises et de l'État. Aucun de ces deux points de vue contrastés n'est d'une grande utilité pour la compréhension des rapportscomplexes entre les SIG et la société. Cet article soutient que les SIG deviennent de plus en plus un moyen de communiquer au grand public des informations fondamentales sur la société et l'environnement. En redéfinissant les SIG comme un instrument médiatique, cet article conduit une analyse tétradique sur leurs implications sociales sur la base de l'application de la loi des médias de Marshall McLuhan. L'analyse expose la nature paradoxale et ambivalente de la technologie des SIG. Pour que les SIC puissent aider à réaliser les idéaux démocratiques dans la société, cet article demande un changement de perspective, afin de les envisager moins comme des instruments pour la résolution de problèmes et plus comme des formes de communication. Ce changement de raison d'être, d'un instrument à une forme de communication, nous permet de réaliser un examen plus critique et holistique de la façon dont l'espace, les personnes et l'environnement ont été représentés, manipulés et visualisés dans les SIG. II favorise ainsi une application plus critique et plus démocratique des SIG.

The Canadian Geographer / Le Géographe canadien 47, no 1 (2003) 5-17

(C) / Canadian Association of Geographers / L'Association canadienne des géographes 


\section{Introduction}

With the wide-ranging applications of $\mathrm{GIS}^{1}$ that now exist in various facets of society, especially their increasing institutionalization in government agencies at all levels (Masser and Onsrud 1993; Campbell and Masser 1995; Craglia and Masser 1995; Monmonier 1998), the social implications of information technology in general and GIS technology in particular have been debated throughout the 1990s and beyond among scholars in several disciplines (Chrisman 1987, 1997; Campari and Frank 1994; Coyne 1995; Sheppard 1995; Pickles 1995, 1997; NCGIA 1996; Harvey 1997; Couclelis 1998; Mugerauer 1998; Yapa 1998; Schuurman 1999, 2000). The traditional conceptualization of GIS as neutral, value-free tools has increasingly been challenged by critical scholars, yet no consensus exists on the societal impacts of GIS technology. Although these societal impacts have been listed as one of the key elements of the National Science Foundation-sponsored Varenius project under the banner of 'geographies of the information society' (Sheppard et al. 1999), our current understanding on this topic remains fragmented, and there exists no general framework to tie together all the diverse views. Indeed, as Openshaw (1996) has so aptly summarized, the discussions on GIS and society have made 'a lot of fuss about very little that matters and not enough about that which does'.

The goal of this paper is to contribute to our understanding of the relationship between GIS and society. By reconceptualizing the role of GIS as media for communicating environmental and social reality, this paper applies Marshall McLuhan's law of media (McLuhan and McLuhan 1988) to conduct a tetradic analysis of the complex relationship between GIS and society and thus aims to establish a general conceptual framework, both to examine the social implications of GIS technology and to provide a critical guideline for the practice of GIS in society.

The paper is organized into six sections. After this brief introduction, a new conceptualization of GIS as media is presented in the second section. McLuhan's law of media is introduced in the third section, and the fourth section uses that law to conduct a comprehensive analysis of the effects of GIS on society. Further discussions on technological ambivalence are presented in the fifth sec- tion, followed by concluding remarks in the last section.

\section{GIS as New Media ${ }^{2}$}

Understanding the relationship between GIS and society is a daunting task, as both terms mean different things to different people and the relationship between the two is similarly debatable. A review of the definitions of GIS in the early 1990s (Maguire 1991) reveals that at least 25 different definitions were, at that time, widely circulated in the GIS literature. The concept of society is even more elusive, considering the different theories of society developed by social scientists and theorists (Giddens 1984). Although it is beyond the scope of this paper to resolve the inconsistencies among these different conceptualizations of GIS and of society, it is crucial to re-examine the meaning of GIS in the light of developments that have occurred in the past five years in order to better understand its impacts on society.

The dazzling development of GIS technology in recent years has rendered each of the traditional, mostly instrumental views of GIS-as spatial database, mapping tool and spatial analytical tool-inadequate to capture the essence of this technology and its social implications. Each year, innovative developers offer new software packages that are easier to use, more powerful and more easily adopted by users with minimal training. GIS and mapping tools are increasingly available on the World Wide Web (WWW), and an increasing number of sites offer advanced GIS services, such as route-finding and geocoding. In-vehicle navigation systems using GIS technology are becoming part of our daily lives (Cowen 1994). In the next two years, cell phones in the US will be required to be geographically enabled-to be able to report their current location to an accuracy of $100 \mathrm{~m}$-in the interests of accurate response to emergency calls. New imagery with spatial resolutions as fine as $1 \mathrm{~m}$ is becoming available from commercial sources and is being distributed through new mechanisms, such as distributed geolibraries and spatial data clearinghouses (NRC 1993, 1999). New methods of data documentation are being used to support widespread sharing of spatial data via the Internet. These new trends contrast sharply with the earlier view, which prevailed into the early 1990s, of GIS

The Canadian Geographer / Le Géographe canadien 47, no 1 (2003) 
as tools contained within a stand-alone computing system, serving the needs of their professional users by performing various forms of analysis too tedious, time-consuming or expensive to perform by hand, on data collected and assembled for the purpose.

Media are generally understood as means of sending messages or communicating information to the general public, and mass media are the instruments by which mass communication takes place in modern societies. Mass media are also the most effective means of broadcasting information to large numbers of people in a short period of time. In a very general sense, GIS can be understood as a new technological species in an already crowded media jungle, a species specifically focused on the communication of geographic information. The fact that GIS communicates geographic information in digital form merely illustrates its consistency with contemporary media, which now make widespread use of digital encoding at various stages. By reconceptualizing GIS as new media, we can gain fresh insights into the relationship between GIS and society, because the impacts of media are much better understood today as a result of years of interdisciplinary research. In this paper, Marshall McLuhan's law of media is invoked to demonstrate how media theories can shed light on the social implications of GIS.

Before doing so, however, it is appropriate to take a close look at the meaning of GIS as new media. This thesis can be broadly understood in at least the following dual senses. First, GIS increasingly have become a means to communicate certain aspects of the real world to the general public. The Environmental Systems Research Institute (ESRI, in Redlands, California) advertises its GIS software products as a 'common language' for speaking about and 'discovering' the world, while Intergraph (Huntsville, Alabama) goes so far as to name its products 'GeoMedia'. The role of communication is superseding the three traditional conceptualizations of GIS noted above (as tools for database management, mapping and spatial analysis), because the impacts of GIS are realized only when results are presented to people on screens or on paper. Thus, communication in its broadest sense must be given the central position when we discuss relationships between GIS and society. Software vendors may have recognized this role of GIS better than many of their customers have done. Although data inventory and database management, automated mapping and spatial analysis are still predominant tasks of most GIS projects, in the end, the goal of all GIS operations is to communicate information to an audience in society. All GIS-related activities serve this final purpose-to communicate; all other functions, such as data storage, management analysis and so on, are intermediate steps serving primarily as means to communicative ends. For example, analysis is what the sender uses to expose what the receiver might not otherwise perceive; database management makes it easier for the receiver to understand the content by using standard structures and metadata.

Second, in the past decade significant changes have occurred in the part played by digital geographic information in people's lives. Sites such as Mapquest provide millions of users every day with customized maps of routes and destinations, and sites such as Terraserver offer digital remotesensing imagery for sale to the general public. The Weather Channel and local television stations present forecasts incorporating geographic information from satellite images and display maps of forecasts from advanced computational models (Monmonier 2000). Airline passengers are presented with dynamic maps of their flight's progress. GIS were even featured prominently in the CBS TV crime-fighting series "The District" (Kaplan 2000). Although humans have always needed to communicate geographic information in describing discoveries, giving directions or registering ownership, recent technological developments appear to have opened a new range of possibilities quite different from what we have gotten used to. Indeed, with the emergence of digital places and digital individuals (Curry 1998), we are witnessing not only Toynbee's (1972) etherialization of history but also the etherialization of geography.

It should be pointed out that emphasis on the communication aspect of GIS has its parallels in cartography. Robinson and Petchenik (1975) first introduced Shannon's communication theory to understand the map-making process. Bertin (1978) further elaborated on linkages between the theory of communication and the theory of graphics. Martin (1996) tried to apply the Robinson-Petchenik communication model of cartography to understanding GIS. By reconceptualizing cartography as 
a language for communication, Tobler (1979) introduced Chomsky's (1957) linguistic theory to develop a 'transformation theory' of the cartographic process. Nyerges (1980) further explored Chomsky's 'deep structure' versus 'surface structure' in both cartographic and GIS contexts. Indeed, the communication paradigm dominated the cartographic research literature even in the 1970s and the 1980s (MacEachren 1995). The recent literature on the basic issues of geographic information science (GISci) has also invoked various linguistic metaphors to study geographic information processing from the perspectives of communication and linguistics (Frank and Mark 1991; Goodchild 2000).

However, the majority of these previous works is framed by a cognitive approach that focuses on perception-related issues in map design. The cognitive approach emphasizes perceptive aspects of both map-readers and designers at the micro(individual) level. In other words, the cognitive approach has engaged us in discussing technically oriented syntax issues (rules and grammars governing the relationships among signifiers); few authors have touched upon the complex and problematic semantic issues in geographic information visualization (the relationship between the signifier and the signified). Using communication theorist James Carey's (1989) words, all these previous works are dominated by the 'transmission view' of communication at the technical level (how information is transmitted across space). What is lacking in the current literature is the 'ritual view' of communication at the cultural and philosophical levels (how information is preserved in time).

This paper will take up the challenge to examine cultural and philosophical implications of GIS in society, using McLuhan's law of media at the macrolevel. Our current work is conceptually in line with Harley's (1989) ground-breaking work in making the power relationship explicit in the map-making process, and it resonates with the recent literature on maps as social constructions (Crampton 2001). As geographers' earlier works have revealed (Burgess and Gold 1985; Zonn 1990; Hay and Israel 2001), media plays an important role in the public's perception of many critical issues in society. How geography is communicated via the media of GIS obviously demands critical scrutiny.

\section{McLuhan's Law of Media}

Originally trained in literary criticism and medieval literature, Canadian communication theorist Marshall McLuhan made his name in the 1960s and the 1970s with his groundbreaking studies concerning media's impacts on individuals and on society. His studies on media are best represented by his trilogy: The Mechanical Bride-Folklore of Industrial Man (1951); The Gutenburg GalaxyThe Making of Typographic Man (1962); and Understanding Media - The Extension of Man (1964).

In retrospect, McLuhan was celebrated in the 1960 s for the wrong reasons. With the appearance of CNN, MTV, the Internet, and the World Wide Web, McLuhan's writings make much more sense in 1994 than they did in 1964 (Press 1995; Benedetti and DeHart 1997; Biro 2000; Genosko 2000; Horrocks 2000). As a controversial figure caught in a struggle between tradition and modernity, we believe, McLuhan was deserted by the academy too early and too soon. It is time to re-evaluate those of McLuhan's theories that were hotly contested in the late 1960s (Stearn 1967; Crosby and Bond 1968; Finkelstein 1968; Rosenthal 1968). As it is beyond the scope of this paper to present a comprehensive review of McLuhan's complex ideas, readers are referred to Neill (1983), Gordon (1997) and Grosswiler (1997) for general overviews, and to Levinson (1999) and Theall (2001) for McLuhan's relevance for the new digital age led by the Internet. What follows is a brief introduction to McLuhan's law of media, which will be used to examine the social implications of GIS technology.

Although McLuhan's followers regard him as a clairvoyant whose pungent and integrative insights have functioned as goads to contemporary thinkers, he was dismissed in the 1970s and the early 1980s by most social scientists and literary scholars as a marginal man from a marginal country who got it all wrong. Just like his sudden appearance in Woody Allen's Oscarwinning movie, Annie Hall, McLuhan was brought back onto centre stage in media studies in the early 1990s, again hailed by his disciples as a man who used his probes as drills to pierce the crust of humankind's perceptions, constrained and dulled by the technical environment (Benedetti and DeHart 1997; Genosko 2000). McLuhan's obsession with enlightened insights enabled him to make many 
hits using his intellectual handgun, the one-sentence aphorism. Many of McLuhan's catchy phrases-such as 'the global village', 'the medium is the message', and 'the TV treats the eye as the ear'-have become part of the contemporary popular lexicon.

McLuhan and many of his followers believe that there have been three dominant modes of communication throughout human history: oral/speech, writing/printing press, and the electronic medium. Each dominant medium has produced dramatically different psychic and physical impacts on individuals and on society as a whole. McLuhan succinctly summarized these impacts as the law of media, presented in the tetradic framework (Figure 1) in a book coauthored with his son Eric and published posthumously (McLuhan and McLuhan 1988). McLuhan's law of media has four major elements: any innovations in the dominant mode of communication media will invariably (a) intensify/ enhance certain aspects of human faculties or a given culture, while at the same time (b) making certain aspects of human mental abilities or cultural practices obsolete. Furthermore, all media innovations also (c) retrieve a phase of certain human capabilities or cultural practices long ago pushed aside and (d) undergo a reversal when extended beyond the limits of their potential. The four phases of the tetrad manifest, in advance, the

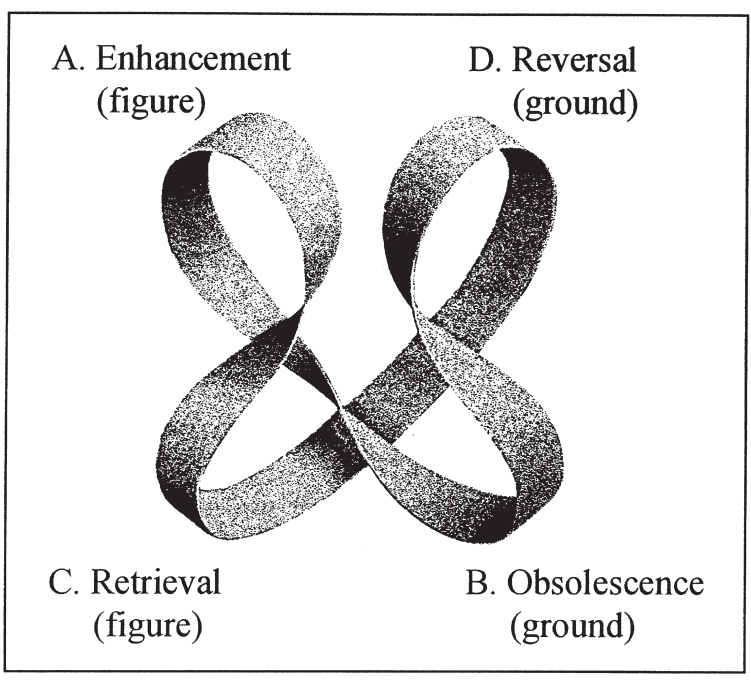

Figure 1

McLuhan's law of media. SOURCE: Modified after McLuhan and McLuhan (1988) cultural impacts of an artefact by showing how total saturated use would produce a reversal of original intent.

McLuhan's law of media interweaves two fundamental elements key to understanding his tetradic model: (1) the distinction between visual and acoustic space and (2) the relationship between figure and ground as outlined in Gestalt psychology. According to McLuhan (1964), dichotomous intellectual discourses are reflections of bifurcated minds deeply rooted in the visual mode of thinking - the result of the Gutenberg (printing press) revolution. McLuhan and Powers (1989) further argue that the 'visual space' mindset leaves little room for alternatives or for participation when no provision is made for two entirely different points of view. The result is usually the exclusion of alternative perspectives. To fully comprehend the new reality mediated by the electronic medium, McLuhan and Powers (1989) call for a fundamental shift from the values of linear thinking (visual, proportional space) to those of the multisensory life (the experience of acoustic space). Visual thinking places information structurally and sequentially-having separate centres with fixed boundaries. Acoustic thinking regards things as interconnected simultaneously-having centres everywhere with boundaries nowhere. Visual thinking is thus centred and bounded. Acoustic thinking is built on holistic and organic ontology. Acoustic space has no cardinal centre, just many centres floating in a cosmic system that honours only diversity. This shift demands that we engage in simultaneous understanding and integral awareness. As one of us has argued elsewhere (Sui 2000), the shift from a predominantly visual metaphor to an aural one is one of the major changes in geographical discourses in the late 20th century. Such a change was made possible by an array of philosophical, technological, and social changes in society. At the very fundamental level, visual and aural thinking entail different sets of epistemological values, orchestrated as by the eye versus the ear. We now know that sound imposes its concreteness on us by immersing and surrounding us in its field and that sound tends always to socialize. Voice is inherently relational and subjective. In contrast, sight entails an object world fixed in space, giving an illusion of permanence. Vision is thus inherently detached and objective.

The Canadian Geographer / Le Géographe canadien 47, no 1 (2003) 
Also implicitly woven into McLuhan's tetrad is the concept of figure/ground, borrowed from Gestalt psychology: enhancement and retrieval as two figures and obsolescence and reversal as two grounds. Visual thinking usually stresses one figure or one ground, but rarely both. Acoustic thinking engages us in double figures and double grounds and enables us simultaneously to evaluate the overall effects of an artefact on society. McLuhan believes that every product of human effort manifests the same four dimensions. His tetrad enables us to reposition ourselves into a holistic perceptive mode-the mode of the dynamically many-centred-and to move away from the monolithic linear visual image. Instead of simplistic utopian and dystopian views, McLuhan's inclusive and irreducible four-part law of media provides a better conceptual framework within which to understand the relationship between GIS and society. As an exploratory probe resting on a set of questions, instead of a bounded theory, the tetrad will facilitate our simultaneous understanding and integral awareness. To confine ourselves to only one metaphor, as most authors have done so far, is to engage in synecdoche-to mistake the part for the whole (Sui 1998).

\section{GIS and Society: A Tetradic Analysis}

If GIS are indeed becoming new media for communicating various forms of social and environmental information in society (Goodchild 2000; Sui and Goodchild 2001), it will be interesting to take a close look at the extent to which McLuhan's law of media can be applied to examine the impacts of GIS. Tying the relationship between GIS and society to McLuhan's law of media, we will conduct a tetradic analysis by answering the four questions raised in McLuhan's framework. In this paper, society is conceptualized as a collection of complex, interacting webs of social, economic, political and cultural relationships among individuals and institutions.

\section{GIS and society I: what do GIS enhance?}

It is common knowledge, and generally agreed upon by GIS practitioners and critics alike, that GIS have greatly facilitated data inventory and database management of georeferenced information. GIS also provide users with a variety of exciting new tools for analyzing and visualizing geographic information. If we follow McLuhan's axiom that all media are extensions of people, GIS have definitely extended human faculties in several ways. As far as drawing and mapping are concerned, GIS have extended our hands for production of a variety of virtual and real maps. As far as fieldwork is concerned, GIS have extended our eyes through increasing integration with remote sensing and aerial photography. As far as navigation skills are concerned, GIS have extended the brain's powers through increased adoption of car navigation systems and integration of real-time global positioning systems (GPSs). As far as human central nervous systems are concerned, GIS have extended our minds and thinking abilities through integration with artificial intelligence, expert systems, various kinds of spatial analysis and modeling and even the incorporation of emotions into computing processes (Openshaw and Openshaw 1997; Picard 1997). In many ways, GIS have also enhanced accessibility of geographic information for a wide range of users throughout society. Since most GIS courses are offered by geography departments in North America (Morgan 1996), GIS have undoubtedly improved the visibility of geography both in the academy and in society.

Although numerous organizational issues still need to be resolved, the rapid diffusion of GIS into various government agencies and corporate settings not only has greatly enhanced application of georeferenced information in interesting and exciting ways, but has also promoted GIS as a new science in and of itself (Wright et al. 1997). From a broader perspective, GIS must be understood as a part of the information revolution that has transformed our society from an industrial into a postindustrial one. During this process, GIS certainly have become part of society's transition from the mode of production to the mode of information (Poster 1990).

\section{GIS and society II: what do GIS make obsolete?}

In opposition to predominant techno-utopian views, McLuhan's scheme further proposes that new media and technologies do not simply extend our various mental and physical faculties. To the contrary, media also simultaneously make obsolete (or 'amputate') various social practices and human faculties. By 'obsolescence', McLuhan does not mean the total disappearance or outdating of certain social practices, but rather that certain

The Canadian Geographer / Le Géographe canadien 47, no 1 (2003) 
media or social practices are no longer dominant. GIS do not simply extend our mapping capabilities without cost. GIS also simultaneously make obsolete many aspects of traditional cartographic practices, such as the use of drawing pens. In other words, GIS are killing certain aspects of cartography as we know it (Goodchild 1999). Likewise, for an increasing number of GIS users, the technology has made obsolete many traditional field techniques and has even partially eliminated the desire to collect first-hand data, as so many secondary data are available in digital format on CD or via the Web. The reliance on secondary data for research and social applications has profound legal, ethical and methodological implications (Sheppard 1993).

During the past decade, we have witnessed more and more geographic research being conducted in the office at the computer screen, rather than in the field. Agencies such as the US Forest Service, which used to rely heavily on personnel located in the field, now place more and more emphasis on digital information management in the office as a primary agency function. Whether this results in better forest management is clearly an increasingly important question. Whether the new development in field technologies ${ }^{3}$ can reverse this trend remains to be seen.

The impacts of GIS on analytical and navigational skills are even easier to detect. Just as the use of calculator and cash register has 'amputated' mental arithmetic among some users, the increasing deployment of technologies such as GPS and wireless computing in the field may be 'amputating' or making obsolete valued skills of directionfinding and navigation. Today, we can easily generate a digital elevation model (DEM) by simply pressing a few buttons in ArcView, using either the inverse distance or Kriging method, but GIS users often express more interest in learning how to operate a particular software package to produce impressive output than in understanding how its algorithms work. One of the consequences of access to powerful GIS tools may be a greater interest in doing the thing right rather than in doing the right thing. In McLuhan's words, the medium is indeed becoming the message.

\section{GIS and society III: what do GIS retrieve?}

The third element of McLuhan's framework is that new media also retrieve certain practices and cul- tural elements long regarded as obsolete. One of the grand themes of his thesis-and perhaps the most controversial-holds that electronic media are breaking from the dominant linear thinking patterns of the printed word, which itself made obsolete the oral tradition as the dominant mode of communication in many facets of society. In sharp contrast to the printing press, which is a predominately visual medium, electronic media are aural and tactile, geared toward the ear or other senses. That is, electronic media are retrieving many traits of the oral culture-a phenomenon that Ong (1982) calls the second orality.

In the context of GIS, the retrieval aspect has gone through several stages. The initial success of GIS relied heavily on integration of automated mapping and database-management systems for data inventory and database-management purposes. Deficiencies in analytical capabilities motivated the GIS community to retrieve many of the techniques developed during the quantitative revolution, as evidenced by efforts during the late 1980s and early 1990s to link GIS with spatial analysis and modeling tools (Goodchild et al. 1992). These efforts to improve the analytical capabilities of GIS have led to the realization that our current conceptualizations of space and time in GIS are incomplete (Rundstrom 1991, 1995; Huffman 1996; NCGIA 1996; Pickles 1998; Miller 2000). Thus, the second major retrieval within GIS is the study and incorporation of naïve geography, as evidenced by the National Center for Geographic Information and Analysis (NCGIA) research initiatives and the Varenius project's focus on cognitive models of the geographic world and their potential role in development of better tools (Egenhofer and Mark 1995; Mark et al. 1999). The limits of computation have revealed the vast terrae incognitae that humanistic geographers have explored using nonscientific rules (Sui 2001). The third major retrieval effort within GIS is the recent endeavour by GIS researchers, as well as critical social theorists, to link GIS to various aspects of social theories in order to guide current practices, as evidenced by NCGIA's initiative 19 (I-19) and the emphasis in the Varenius project on the emerging geography of the information society. These research efforts obviously have moved away from the dominance of mapping (for the eye) to a more multisense/ multimedia mode of representing different voices and narratives (for the ear). This trajectory of GIS 
and GISci development is interpreted as a reflection of McLuhan's theme of the retrieval of orality by electronic media.

Perhaps even more significant is that the retrieval capabilities of GIS remind us of shifting metaphors in our social discourse-from the visual mode, dominated by the eye, to the aural mode, dominated by the ear. What GIS have retrieved is re-emphasis on the role of speech, narrative and even rhetoric. GIS as media do not simply present beautiful images or maps for people to look at; behind these pictures is usually a story to be read or a speech to be heard. Aspects of aurality also appear, either consciously or unconsciously, in GIS design (Gould 1994). In many applications, GIS have increasingly become rhetorical devices to create meaning and discourse (Sui 1998). To follow and understand GIS rhetoric, which is similar to that Smith (1996) demonstrates for geographical writings in general, we must understand their tropes and modes and their roles in determining our conclusions. Instead of regarding GIS as 'a distant mirror' faithfully reflecting reality (Pickles 1999), it is perhaps more appropriate to treat GIS as 'a close dialogue' among different players in society. By shifting our ocular metaphor to an aural one, we can be more sensitive to different voices and, possibly, to silences as well.

At a more anecdotal level, it is perhaps not coincidental that GIS software packages have been named Idrisi and research projects have been called the Alexandria Digital Library or the Varenius project. These names also work to retrieve aspects of the past and to emphasize connections between contemporary technology and much older concerns.

\section{GIS and society IV: what do GIS reverse into?}

The last proposition of McLuhan's law of media is that when a medium is pushed to its limit, it will be reversed into the opposite of what it was originally designed for. In McLuhan's $(1964,23)$ words, '[W]e become what we behold; we first make the tools, then the tools will make us'. Using numerous examples of human artefacts and technologies, McLuhan tries to show that in the beginning, media are extensions of people, but in time people become extensions of media. When a medium is pushed to its limit, it becomes the message itself. Critical scholars of technology give this process a variety of different names, such as 'Marx's alienation' (Ollman 1977), 'reversed adoption' (Veregin 1995), 'technopoly' (Postman 1992) and 'colonization of lifeworld' (Habermas 1987). Echoing what Wittgenstein demonstrated for language, McLuhan proposes that when a medium is pushed to its limit, it is no longer just the vehicle, but also the driver. Indeed, when we surrender our goals and social practices to the technical requirements of a machine, the technology itself becomes what Max Weber called an 'iron cage' (Scaff 1989). When this occurs, the cage locks up our imagination and creativity. To McLuhan and many of his followers, media are not simply 'making-aware' agents but also-and perhaps more importantly-'makinghappen' agents. Taken in isolation, this reversal concept may easily be construed as a technologydeterministic argument. In fact, McLuhan's law of media only makes sense when its four elements are taken into consideration as a whole in his tetradic framework.

In the context of GIS, what worries most social theorists is that computerization of the natural and cultural may inevitably lead to the naturalization and culturalization of the computerized. This trend, if not deconstructed critically, will have serious social and philosophical consequences. In more and more real-world situations, we have witnessed incidents where organizational mandates or problems themselves are modified to meet requirements of GIS technology. Data models force representations on the world by requiring them to follow certain rules, such as separation of complex systems into geographical layers or imposition of crisp, Boolean categories on systems which are inherently fuzzy. If the only available means of solving a problem is a GIS with no way of representing uncertainty, it seems much simpler to ignore uncertainty than to insist on better tools.

When GIS are reversed into their opposites, they cease to promote democratic practices in society. Instead, GIS developments and applications are driven by corporate greed or the state's insatiable desire to survey and collect intrusive information from ordinary citizens (Goss 1995). Consequently, we become slaves of our media, instead of using media to serve our higher goals and aspirations. Some critics warn that GIS, coupled with other information technologies, will become a super Panopticon to monitor and survey, rather than to 
help, ordinary citizens, especially the truly disadvantaged (Sui 1998).

Perhaps even more problematic are the philosophical consequences that result when GIS reverse into their opposites. Given their increasingly numerous and versatile visualization capabilities, GIS may give users a false sense of what is real and thus a very shaky ontology (Gregory 1994; Raper 1997). Even more troubling is that these pictures make people feel more real-hyperreal, which is, in fact, unreal. Based upon their studies of the TV advertising industry, Mitroff and Bennis (1993) find that deliberate manufacturing of falsehood and fantasy is not only profitable but has become part of our culture, as electronic media become the dominant mode of representation. They further point out that two kinds of unreality are produced: (1) artificial reality, in which it is often difficult to differentiate between actual and virtual worlds, and (2) pseudoreality, in which attractive presentation overwhelms the desire to differentiate the real from the unreal. Turkle $(1995,169)$ terms the first form of unreality the 'Disneyland Effect (the artificial seems real)' and the second the 'Artificial Crocodile Effect (the fake seems more compelling than the real)'. These ontological effects have tended to suppress alternative ways of knowing, suggesting that GIS may become a prison which traps us into particular modes of knowing and separates us from the real world and its problems (Curry 1998). To Heidegger (1977), the real danger of the inherent enframing nature of technology comes not from potentially lethal machines or the apparatus of technology itself. Rather, the danger lies in our becoming increasingly blind to alternative ways of looking at things as we turn to technology for solutions to social problems. In this sense, GIS as media represent more than mere exterior aids; they represent interior transformations of consciousness as well. When and if this indeed happens, it would be more apt to say that GIS stands for geographic illusion systems (Couclelis 1996). Indeed, when pushed to their limits, GIS are just the electronic version of Plato's cave: what we see on the screen are only illusions of reality.

\section{Dealing with Technological Ambivalence}

The central theme of McLuhan's law of media states that the effects of media (or technologies in general) on society are inherently paradoxical. As both Tuan (1989) and Tenner (1996) have elucidated with fascinating examples, such paradoxical effects defy simplistic good or bad characterizations from either technological utopian or dystopian perspectives. Instead, we must try to grasp four aspects simultaneously. McLuhan's implicit message is that the social impacts of technology are ambivalent. Excessive use of technologies always leads to the opposite of what they are designed for. In the context of GIS, it is futile to debate whether GIS are good or bad for society. The only meaningful question will be: how can we reveal and deal with the ambivalent nature of GIS applications in society?

The reconceptualization of GIS as new media constitutes a fundamental paradigm shift in current GIS practices, from instrumental rationality to communicative rationality (Habermas 1984, 1987). It has been argued that most current GIS applications are dominated by instrumental rationality, in which GIS have been treated as a value-free and neutral tool to generate objective facts. Under instrumental rationality, the social ends of GIS applications are being facilitated, justified and sometimes even defined by its technical means. Results of GIS applications have been used in practice to validate action without attending to the values embedded in the GIS media. This paper argues that such an implicit instrumental conceptualization of GIS in society has unduly restricted the questions that can be asked and has created a false sense of objectivity in public discourse. McLuhan's work provides us with a powerful framework to understand the social (sometimes unintended) consequences of GIS applications. By re-emphasizing the communicative nature of GIS technology, we can better understand the elusive nature of the GIS language. Furthermore, by appreciating GIS's role as media, we can better understand how individuals and organizations systematically manipulate communications to conceal possible problems and solutions, manipulate consent and trust and misrepresent facts and expectations. GIS technology, like all other media and communication tools, can be abused by individuals and organizations to manipulate results and to legitimate and impose political, economic and social agendas. The shift from instrumental to communicative rationality will enable us to examine more critically how space, people and

The Canadian Geographer / Le Géographe canadien 47, no 1 (2003) 
environment have been represented, manipulated and visualized in GIS, and thus to promote more democratic GIS practice in the social arena.

Although McLuhan successfully identified the ambivalent nature of technological development, the solutions he prescribed are controversial. According to McLuhan, the only way to escape technological paradoxes is to resolutely oppose all technological advances (Kroker 1985; Benedetti and DeHart 1997). This casts McLuhan in the role of latter-day Luddite and is obviously not a viable solution. As everything is rapidly becoming computerized in the emerging information society, humanity as a whole will run deeper and deeper into such technological paradoxes. The tools and technologies we deploy to study society have increasingly become part of the society we try to study using those same tools. This technological self-referentiality, similar in a way to the linguistic self-referentiality exemplified by Russell's paradox ${ }^{4}$ will inevitably make it impossible to provide technical solutions to social problems. To transcend such a technological paradox, we must clearly define and continuously redefine our social goals, not allowing any technologies to dictate what we do and why we do it. Just as Wittgenstein (1922) tries so strenuously to prove that we cannot express everything about language using language itself, we cannot solve social problems using technologies such as GIS alone. The following statement from Wittgenstein's Tractatus LogicoPhilosophicus provides an intriguing perspective on the theme of this paper:

My propositions are elucidatory in this way: he who understands me finally recognizes them as senseless, when he has climbed out through them, on them, over them. (He must so to speak throw away the ladder, after he has climbed up on it.)

He must surmount these propositions; then he sees the world rightly.

Whereof one cannot speak, thereof one must be silent (Wittgenstein 1922, 148).

\section{Concluding Remarks: The Messages of GIS}

The meanings of GIS have undergone several major transformations during the past five years. As
Boorstin (1987) pointed out, the supreme law of the republic of technology is convergence-the tendency for everything to become everything else. In the case of GIS, they have evolved from being an arcane tool for mapping and spatial analysis to becoming an integral part of mass media to communicate geographic information in society. Throughout the 1990s, debates about the social implication of GIS technology shifted from simple attacks on positivism to incorporating more subtle analyses of the effects of the technology (Schuurman 2000). In this paper, we continue to make an effort at such analyses. By reconceptualizing GIS as media, we aim to develop a more synthetic, robust framework to better understand the social implications of GIS technology. The tetradic analysis of GIS as media, conducted using McLuhan's framework, has revealed some interesting hidden messages of GIS, which defy the frequent dichotomous characterization of GIS as either good or bad. Instead, GIS transmit a complex set of messages of simultaneous enhancement, obsolescence, retrieval and reversal in society. By reconceiving GIS as media, we can transcend the instrumental rationality currently rampant among both GIS developers and GIS practitioners and cultivate a more holistic approach to nonlinear relationships between GIS and society. The clear and present danger is not GIS or information technologies, but our blissful ignorance of the implications of what they are going to do to us, because we have concentrated too much on what GIS can do for us. The only sensible way of dealing with this inherent technological ambivalence is to always treat GIS media as means to higher social ends.

It is generally accepted as a truism among students of technological impacts on society that all technologies are, in a philosophical sense, Faustian bargains and that we love technology because our psyches are so narcissistic. Current applications of GIS in society are dominated by the Narcissus myth-we are obsessed by the pretty pictures on the screen-and many GIS Fausts have inadvertently sold their souls to the technologies. Awakening from the Narcissus myth demands nothing short of a phoenix transformation of our consciousness (Buttimer 1993). The reconceptualization of GIS as media reveals the Faustian nature of GIS technology and shows us how we can escape from the Narcissus myth using McLuhan's law of

The Canadian Geographer / Le Géographe canadien 47, no 1 (2003) 
media. Such an intellectual exercise is aimed at making GIS a real phoenix, rising out of the deconstructive ashes to new heights. Only by such a transformation in our consciousness can we make GIS into a Noah's Ark with which to survive the current information flood.

\section{Acknowledgements}

We thank Helen Couclelis, Jonathan Phillips, Paul Adams, Rush Cohen, Judith White and Daniel Overton for providing critical comments on an earlier version of this paper, and Bing Lu for research assistance. Constructive comments from two anonymous reviewers are also gratefully acknowledged. The Varenius project and the Alexandria Digital Library are supported through cooperative agreements between the University of California, Santa Barbara, and the US National Science Foundation.

\section{Notes}

1 'GIS' are used as a plural in this paper.

2 This section draws on our recent editorial in the International Journal of Geographical Information Science; see Sui and Goodchild (2001) for details.

3 Visit the NCGIA's Web site for the details of Project Battuta.

4 Russell's paradox is based on examples like this: Consider a group of barbers who shave only those men who do not shave themselves. Suppose there is a barber in this collection who does not shave himself; then, by the definition of the collection, he must shave himself. But no barber in the collection can shave himself. (If so, he would be a man who does shave men who shave themselves.)

\section{References}

BENEDETTI, P. and DEHART, N. 1997 Forward through the Rearview Mirror: Reflections on and by Marshall McLuhan (Cambridge, MA: MIT Press)

BERTIN, J. 1978 'Theory of communication and theory of the graphic' International Yearbook of Cartography 28, 118-126

BIRO, G.M. 2000 Marshall McLuhan Meets the Millennium Bug (New York: Uplevel Publishing)

BOORSTIN, D.J. 1987 Hidden History (New York: Harper and Row)

BuRgESS, J. and GOLD, J.R. 1985 Geography, the Media, and Popular Culture (New York: St. Martin's Press)

BUtTImeR, A. 1993 Geography and the Human Spirit (Baltimore: John Hopkins University Press)

CAMPARI, I. and FRANK, A.U. 1994 'Cultural differences in GIS: a basic approach' in EGIS'94 (Proceedings of European GIS Conference), ed J. Harts, H.F.L. Ottens and H.J. Scholten (Utrecht, the Netherlands: EGIS Foundation) 10-16

CAMPBelL, H. and MASSER, I. 1995 GIS and Organizations: How Effective Are GIS in Practice? (London: Taylor and Francis)

CAREY, J.W. 1989 Communication as Culture: Essays on Media and Society (Boston: Unwin Hyman)

сномsкy, N. 1957 Syntactic Structures (The Hague: Mouton)

CHRISMAN, N.R. 1987 'Design of geographic information systems based on social and cultural goals' Photogrammetric Engineering and Remote Sensing 53, 1367-1370

-. 1997 Exploring Geographic Information Systems (New York: John Wiley and Sons)
COUCLELIS, H. 1996 'Geographic illusion systems: towards a (very partial) research agenda for GIS in the information age' in GIS and Society: The Social Implications of How People, Space, and Environment Are Represented in GIS ed T. Harris and D. Weiner, Technical Report 96-7 (Santa Barbara, CA: National Center for Geographic Information and Analysis) D12-13

-. 1998 'Spatial information technologies and societal problems' in Geographic Information Research: Trans-Atlantic Perspectives, ed M. Craglia and H. Onsrud (London: Taylor and Francis) 15-24

COWEN, D.J. 1994 'The importance of GIS for the average person' Proceedings of First Federal Geographic Technology Conference, Washington, DC 7-11

COYNE, R. 1995 Designing Information Technology in the Postmodern Age: From Method to Metaphor (Cambridge, MA: MIT Press)

CRAGLIA, M. and MASSER, I. 1995 GIS Diffusion: The Adoption of Use of Geographical Information Systems in Local Government in Europe (London: Taylor and Francis)

CRAMPTON, J.W. 2001 'Maps as social constructions: power, communication, and visualization' Progress in Human Geography 25(2), 235-252

CROSBY, H.H. and BOND, G.R. 1968 The McLuhan Explosion: A Casebook on Marshall McLuhan and Understanding Media (New York: American Book Co.)

CURRY, M.R. 1998 Digital Places: Living with Geographic Information Technologies (London: Blackwell)

EGENHOFER, M. and MARK, D.M. 1995 'Naive geography' in Spatial Information Theory: A Theoretical Basis for GIS, ed A.U. Frank and W. Kuhn, Lecture Notes in Computer Science 988 (Berlin: Springer-Verlag) 1-15

FinKelSTEIN, S. 1968 Sense and Nonsense of McLuhan (New York: International Publishers)

FRANK, A.U. and MARK, D.M. 1991 'Language issues for GIS' in Geographical Information Systems: Principles and Applications, ed D.J. Maguire, M.F. Goodchild and D.W. Rhind (Harlow: Longman Scientific and Technical) 147-163

GENOSKO, G. 2000 McLuhan and Baudrillard: The Masters of Implosion (New York: Routledge)

GIDDENS, A. 1984 The Constitution of Society (Oxford: Polity Press)

GOODCHILD, M.F. 1999 'GIS and geography: elements of a debate' Yearbook of the Association of Pacific Coast Geographers 60, 150-157

-. 2000 'Communicating geographic information in a digital age' in Annals of the Association of American Geographers 90(2), 344-355

GOODCHILD, M.F., HAINING, R. and WISE, S. 1992 'Integrating GIS and spatial data: problems and possibilities' International Journal of Geographical Information Systems 6, 407-23

GORDON, W.T. 1997 McLuhan for Beginners (Toronto: Writers and Readers)

Goss, J. 1995 'We know who you are and we know where you live: the instrumental rationality of geodemographic systems' Economic Geography 71, 171-198

GouLD, M.D. 1994 'GIS design: a hermeneutic view' Photogrammetric Engineering and Remote Sensing 60, 1105-1115

GREGORY, D. 1994 Geographical Imaginations (Cambridge, MA: Blackwell) GROSSWILER, P. 1997 The Method is the Message: Rethinking McLuhan through Critical Theory (New York: Black Rose Books Ltd.)

HABERMAS, J. 1984 The Theory of Communicative Action Vol. 1 (Boston: Beacon Press)

-. 1987 The Theory of Communicative Action Vol. 2 (Boston: Beacon Press) 
HARLEY, B. 1989 'Deconstructing the map' Cartographica 26, 1-20 HARVEY, F. 1997 'From geographic holism to geographic information system' The Professional Geographer 49(1), 77-85

HAY, I. and ISRAEL, M. 2001 "“Newsmaking geography”: Communicating geography through the media' Applied Geography 21(2), $107-125$

HeIDEgGER, M. 1977 The Question Concerning Technology, and Other Essays (New York: Garland)

HORROCKS, C. 2000 Marshall McLuhan and Virtuality (New York: Totem Books)

HUFFMAN, N.H. 1996 'You can't get here from there: reconstructing the relevancy of design in postmodernism' in Cartographic Design: Theoretical and Practical Perspectives, ed C.H. Wood and C.P. Keller (New York: John Wiley and Sons) 35-53

KAPLAN, к. 2000 'Mapping software has role in "The District"' Los Angeles Times 16 October, D11

KROKER, A. 1985 Technology and the Canadian Mind: Innis/McLuhan/ Grant (New York: St. Martin's Press)

LEVInSon, P. 1999 Digital McLuhan: A Guide to the Information Millennium (New York: Routledge)

maCEACHREN, A.m. 1995 How Maps Work: Representation, Visualization, and Design (New York: Guilford Press)

MAGUIRE, D.J. 1991 'An overview and definition of GIS' in Geographical Information Systems: Principles and Applications, ed D.J. Maguire, M.F. Goodchild and D.W. Rhind (Harlow: Longman Scientific and Technical) 9-20

MAPQUEST http://www.mapquest.com (last accessed 13 January 2003)

MARK, D.M., FREKSA, C., HIRTLE, S.C., LLOYD, R. and TVERSKY, B. 1999 'Cognitive models of geographic space' International Journal of Geographical Information Science 13(8), 747-774

MARTIN, D. 1996 Geographic Information Systems: Socioeconomic Applications 2nd ed. (London: Routledge)

MASSER, I. and ONSRUD, H.J. 1993 Diffusion and Use for Geographic Information Technologies (Boston: Kluwer Academic Press)

MCLUHAN, M. 1951 The Mechanical Bride: Folklore of Industrial Man (New York: Vanguard Press)

- 1962 The Gutenberg Galaxy: The Making of Typographic Man (Toronto: University of Toronto Press)

-. 1964 Understanding Media: The Extension of Man (London: Sphere Books)

mcluhan, m. and mcluhan, E. 1988 Laws of Media: The New Science (Toronto: University of Toronto Press)

MCLUHAN, M. and POWERS, B.R. 1989 The Global Village: Transformations in World Life and Media in the 21st Century (New York: Oxford University Press)

MILLER, H.J. 2000 'Geographic representations in spatial analysis' Journal of Geographical Systems 2(1), 55-60

MITROFF, I.I. and BENNIS, w. 1993 The Unreality Industry: The Deliberate Manufacturing of Falsehood and What It Is Doing to Our Lives (New York: Oxford University Press)

MONMONIER, M. 1998 'The three Rs of GIS-based site selection: representation, resistance and ridicule' in Policy Issues in Modern Cartography, ed D.R.F. Taylor (London: Pergamon) 164-175

-. 2000 Air Apparent: How Meteorologists Learned to Map, Predict, and Dramatize Weather (Chicago: University of Chicago Press)

MORGAN, J.M. 1996 Directory of Academic GIS Education (Dubuque, IA: Kendall/Hunt Publishing Co.)

MUGERAUER, R. 1998 'Qualitative GIS: to mediate, not dominate' in Information, Place, and Cyberspace: Issues in Accessibility ed D.G. Janelle and D.C. Hodge (Berlin: Springer) 317-338
NATIONAL CENTER FOR GEOGRAPHIC INFORMATION AND ANALYSIS (NCGIA) 1996 Advancing Geographic Information Science: A Research Agenda Santa Barbara, CA: National Center for Geographic Information and Analysis http://www.ncgia.ucsb.edu/secure/main.html

—. Project Battuta http://dg.statlab.iastate.edu/dg/ (last accessed 13 January 2003)

NATIONAL RESEARCH COUNCIL (NRC) 1993 Toward a Coordinated Spatial Data Infrastructure for the Nation (Washington, DC: National Academy Press)

-. 1999 Distributed Geolibraries: Spatial Information Resources (Washington, DC: National Academy Press)

NEILL, S.D. 1983 Clarifying McLuhan (Westport, CT: Greenwood Press)

NYERGES, T.L. 1980 'Modeling the structure of cartographic information for query processing' Ph.D. dissertation, Ohio State University

ollman, B. 1977 Alienation: Marx's Conception of Man in Capitalist Society (New York: Cambridge University Press)

ONG, w.J. 1982 Orality and Literacy: The Technologizing of the Word (New York: Methuen)

OPENSHAW, s. 1996 'GIS and society: a lot of fuss about very little that matters and not enough about that which does' in GIS and Society: The Social Implications of How People, Space, and Environment Are Represented in GIS ed T. Harris and D. Weiner, Technical Report 96-7 (Santa Barbara, CA: National Center for Geographic Information and Analysis) D54-58

OPENSHAW, s. and OPENSHAW, c. 1997 Artificial Intelligence in Geography (New York: John Wiley and Sons)

PICARD, R.w. 1997 Affective Computing (Cambridge, MA: MIT Press)

PICKLES, J. 1995 Ground Truth: The Social Implications of Geographic Information Systems (New York: Guilford Press)

- 1997 'Tool or science? GIS, technoscience, and theoretical turn' Annals of the Association of American Geographers 87(2), 363-372

—. 1998 'Arguments, debates, and dialogues: the GIS-social theory debate and the concern for alternatives' in Geographical Information Systems: Principles, Techniques, Management and Applications ed P.A. Longley, M.F. Goodchild, D.J. Maguire and D.W. Rhind (New York: John Wiley and Sons) 49-60

-. 1999 'Cartography, digital transitions, and questions of history' in Proceedings, International Cartographic Association Assembly, Ottawa, August (Ottawa: Canadian Institute of Geomatics) CD-ROM

POSTMAN, N. 1992 Technopoly: The Surrender of Culture to Technology (New York: Knopf)

POSTER, M. 1990 The Mode of Information: Poststructuralism and Social Context (Chicago: University of Chicago Press)

PRESS, L. 1995 'McLuhan meets the Net' Communications of the ACM 38(7), 15-20

RAPER, J. 1997 'Unresolved problems of spatial representation' in Advances in GIS Research II ed M.J. Kraak and M. Molenaar (London: Taylor and Francis) 917-928

ROBINSON, A.H. and PETCHENICK, B.B. 1975 'The map as a communication system' The Cartographic Journal 12(1), 7-14

Rosenthal, R. 1968 McLuhan: Pro and Con (Baltimore: Penguin)

RUNDSTROM, R. 1991 'Mapping, postmodernism, indigenous people, and the changing direction of North American cartography' Cartographica $28,1-12$

—. 1995 'GIS, indigenous peoples, and epistemological diversity' Cartography and Geographic Information Systems 22(1), 45-57

SCAFF, L.A. 1989 Fleeing the Iron Cage: Culture, Politics, and Modernity in the Thought of Max Weber (Berkeley: University of California Press) 
schuUrman, N. 1999 Critical GIS: Theorizing an Emerging Science Cartographica Monograph no. 53 (Toronto: University of Toronto Press)

-. 2000 'Trouble in the heartland: GIS and its critics in the 1990s' Progress in Human Geography 24(4): 569-590

SHEPPARD, E. 1993 'Automated geography: what kind of geography for what kind of society?' The Professional Geographer 45, 457-460

- 1995 'GIS and society: towards a research agenda' Cartography and Geographic Information Systems 22, 5-16

SHEPPARD, E., COUCLELIS, H., GRAHAM, S., HARRINGTON, w. and ONSRUD, H. 1999 'Geographies of the information society' International Journal of Geographical Information Science 13(8), 797-824

SMITH, J.M. 1996 'Geographic rhetoric: modes and tropes of appeal' Annals of the Association of American Geographers 86(1), 1-20

STEARN, G. E. 1967 McLuhan: Hot and Cool (New York: Dial Press)

sul, D.z. 1998 'Deconstructing virtual cities: from unreality to hyperrealtiy' Urban Geography 19(7), 657-676

-. 2000 'Visuality, aurality, and the shifting metaphors in geographic thought in the late 20th century' Annals of the Association of American Geographers 90(2), 322-343

-. 2001 'Terrae incognitae and limits of computation: whither GIScience?' Computers, Environment, and Urban Systems 29(5) 529-533

sul, D.z. and GoodChILD, M.F. 2001 'Are GIS becoming new media?' International Journal of Geographical Information Science 15(5), 387-390
TENNER, E. 1996 Why Things Bite Back: Technology and the Revenge of Unintended Consequences (New York: Knopf)

TERRASERVER http://www.terraserver.com

THEALL, D.F. 2001 The Virtual Marshall McLuhan (Montreal: McGill University Press)

TOBLER, W.R. 1979 'A transformational view of cartography' The American Cartographer 6(2), 101-106

TOYNBEE, A. 1972 A Study of History Updated ed. (New York: Weathervane Books)

TUAN, Y.F. 1989 Morality and Imagination: Paradoxes of Progress (Madison: The University of Wisconsin Press)

TURKLE, S. 1995 Life on the Screen: Identity in the Age of the Internet (New York: Simon and Schuster)

VEREGIN, H. 1995 'Computer innovation and adoption in geography: A critique of conventional technological models' in Ground Truth: Social Implications of Geographic Information Systems ed J. Pickles (New York: The Guilford Press) 88-112

witTGenstein, L. 1922 Tractatus Logico-Philosophicus (London: Routledge and Kegan Paul Ltd.)

WRIGHT, D.J., GOODCHILD, M.F. and PROCTOR, J.D. 1997 'GIS: tool or science?' Annals of the Association of American Geographers 87, 346-362

YAPA, L. 1998 'Why GIS needs postmodern social theory, and vice versa' in Policy Issues in Modern Cartography ed D.R.F. Taylor (London: Pergamon) 191-201

zonN, L. 1990 Place Images in Media: Portrayal, Experience, and Meaning (Savage, MD: Rowman and Littlefield) 